\title{
LEGO blocks as a gamification tool
}

\author{
Domínguez Vila, Trinidad $^{\text {a }}$; Alén González, Elisa ${ }^{a}$ and de Carlos Villamarín, Pablo ${ }^{a}$ \\ ${ }^{a}$ Department of Business Management and Marketing, University of Vigo, Spain
}

\begin{abstract}
New teaching methodologie,s with a more active participation of the student,s are increasingly present in the educational field. One of the best known is gamification, which refers to learning through play. A tool used in this methodology are the LEGO blocks. In this paper, an analysis of the students' skills developed by LEGO blocks learning is carried out in two dimensions: self-connection and communication with others. A sample composed of Bachelor's Degree in Computer Engineering and a Master's Degree in Teaching students is analyzed, in order to identify common behavioral patterns through a cluster analysis. Conclude that the use of this tool is is highly valued by students in terms of the development of the own dynamic as well as the implicit learnin that it propose.
\end{abstract}

Keywords: LEGO blocks; gamification; game-design; self-connectiona; connection with others. 


\section{Introduction}

Various pedagogical movements currently advocate the use of different methodologies that involve more active student participation in the learning process by encompassing elements as relevant in the process as critical thinking or assimilation, understanding and the application of content among others (Bonwell \& Eison, 1991, Scannapieco, 1997). Gamebased learning or gamification is one of these methodologies. It leads to positive experiences in the learning process (Connolly et al., 2012) while reinforcing and consolidating knowledge through practice. Gamification is based on the use of mechanics, elements and game design techniques to engage users and solve problems (Zichermann \& Cunningham, 2011; Werbach \& Hunter, 2012 ). Through it, one may influence the behavior of people, thanks to the fact that it produces and creates experiences, feelings of domination and autonomy (Hamari \& Koivisto, 2013).

One of the games used to this end are LEGO blocks. It is associated with creativity, imagination, teamwork, problem solving or rewards among others (Gadomska, 2015). Teachers have already included it in the curricula because its dynamic is very motivating, and it facilitates learning (Buckley, 2015; Erwin, 2000; McNamara et al., 1999). Different methods are used with LEGO blocks, but they all generally work on the idea of unity, coherence and cohesion as a metaphor for the construction of meaning in students. What is more, they act as a bridge of union (Buckley, 2015; Gadomska, 2015). Papert (1980) emphasizes that students learn more effectively when they can manipulate tangible materials that facilitate both physical and mental simulations in problem-solving ( $\mathrm{Li}$ et al., 2016).

This paper analyzes the use of a LEGO dynamic on the student learning process. It aims to work on communication and teamwork, to later analyze the results grouped into three large blocks: variables linked to self-connection, connection with others and the own dynamic.

\section{Lego as a Gamification Tool}

According to the methodology, the objectives of LEGO are divergent. The same end is not sought when LEGO is applied in the humanistic field rather than the scientific field. In the latter, it influences engineering design by facilitating student openness in ultimate problemsolving; it interiorizes concepts and scientific terminologies at a greater flow (Bethke \& Rogers, 2013). "Engineering is the application of science to problem solving, and design is the creative expression of knowledge" (Li et al., 2016: 144)

We can classify the skills affected by gamification through LEGO into two large groups: self-connection and connections with others. In relation to the former, self-connection, various studies show that the use of Lego creates a facilitating environment. It uses 
dynamics to visualize aspects of reflection on practical situations (Osmond \& Darlington, 2005). At the same time, it produces an apathetic connection in the development of ideas (Papert \& Harel, 1991). This makes it possible to add reflection, which influences critical reflection; but it does so in a creative way that facilitates this process (Gauntlett, 2007, Osmond \& Darlington, 2005). Horwarth and Morrison (1999), like Hunt (2006), agree on the results of their studies, in which the use of LEGO provides tacit knowledge and links theory to practice (All \& Havens, 1997) by facilitating the chance to split difficult concepts into more understandable parts that can be reconstructed.

Concerning the connection with others, the dynamics with LEGO emphasizes communication, understood as the connection with others, through a supporting medium. However, various handicaps may appear. Anxiety may be present in the social scope of the work among students (Ruch, 2002), at the place where the dynamics are developed, or the teacher may act as a facilitator during the development of the dynamics (Daines et al.,, 1998). This generates the need to work and delve into conflict resolution and team building. By having to work with their hands, the players explore new ways of constructing more open identity models. This facilitates the use of different communication channels to convey experiences, connecting them with greater flow to other participants (Gauntlett, 2007). Race (2001) advocates the use of LEGO in team building. Once again, however, time constraints were acknowledged as having an impact on the success of the workshop. Therefore, another key element in working with LEGO is inclusion because it is a tool that encompasses individual and collective learning styles about thoughts and learning from diverse points of view (Lawlor \& Handley, 1996).

\subsection{Development of the LEGO Dynamics}

The tools used through LEGO are very broad and varied. This is why we have chosen to select a game focused on improving communication skills and teamwork. The one proposed by Switon is used as a reference for the development of the game (2016: 1).

Game Purpose: to illustrate the importance of clear communication, and allow the group to explore their communication style and make improvements as necessary.

- $\quad$ Materials and Preparation: 2 matching sets of children's building blocks (e.g. Lego), with 10 blocks and 1 base board in each set. Using one set of blocks, build a random object using the 10 blocks, which must then be duplicated.

Time: 45-60 minutes

Group Size: minimum 3 people, up to about 7 (You can have duplicate exercise running in parallel if group is larger, but will need more sets of building blocks). 
- $\quad$ Rules: There are 4 roles in this communication skills game.

o Person A - director. Person A is given the built-up set of blocks, and is the only person who can see the object. It is the director's job to give clear instructions to person B, the runner, so that person $\mathrm{C}$ can build an exact replica of the model.

o Person B - runner. Person B listens to the director's instructions and runs to a different part of the room to where person $\mathrm{C}$ is sitting. The runner then passes on the building instructions, without seeing the building blocks, to Person $\mathrm{C}$, the builder. The runner can make as many trips as required within the time allowed for the exercise.

o Person C - builder. Person C listens to the runner's instructions and builds the object from the set of building blocks. The builder is the only person who can see the object under construction, and building materials.

o Person(s) D - observer(s). Person(s) D observe the communication game, and make notes about what works, what doesn't work, and how people behaved under pressure etc., to pass onto the group later.

A time limit of 15/20 minute is set for exercise. When the time is up, the group is allowed to compare the model and the replica to see how much they match. In general, the replication is very similar to the original. This may cause some discussion. You must allow the group to reflect on what the exercise was like and identify 1 thing they did well, 1 that did not work, and 1 to be improved next time.

The exercise is executed again. One may change or maintain the original roles to see if improvements have been made. Yet we must make sure to build a new "original" model. This simple game of communication skills can be executed several times without losing its learning potential. Teams can add levels of sophistication to their communication, make use of aids such as diagrams, codes, standard procedures and active listening techniques.

In general, elements such as language and bidirectional communication, learning, retentive capacity, strategy design, motivation and self-confidence, as well as order of command or efficiency in the use of resources are all worked on at the same time.

\section{Sample and Results}

The aforementioned dynamic was applied to students in the last year of their Bachelor's Degree in Computer Engineering and those enrolled in a Master's Degree in Teaching throughout the 2016/2017 course. A sample of 61 surveys was obtained from a total of 85 students. Almost $70 \%$ of the answers corresponded to students of the last year of Computer Engineering. The rest corresponded to students of the Master's Degree. 
The methodology was based on a questionnaire, passed upon the completion of the dynamics, with questions on the dynamics linked to self-connections, the connection with others and the own dynamics. A 5-point liker scale was used, in which 1 was not important and 5 was very important. In addition, three open questions were added about the development of the activity itself to obtain feedback for the teacher.

As seen in figure 1, the results are quite homogeneous with low dispersion levels; they present a clearly satisfactory trend at the three levels, i.e., self-connection, connection with others and the development of the own dynamic. Almost all the variables analyzed have values equal to or greater than 4 , which highlights the relevance attributed to establishing a common language, the level of concentration, the design of strategies and a clear common objective.

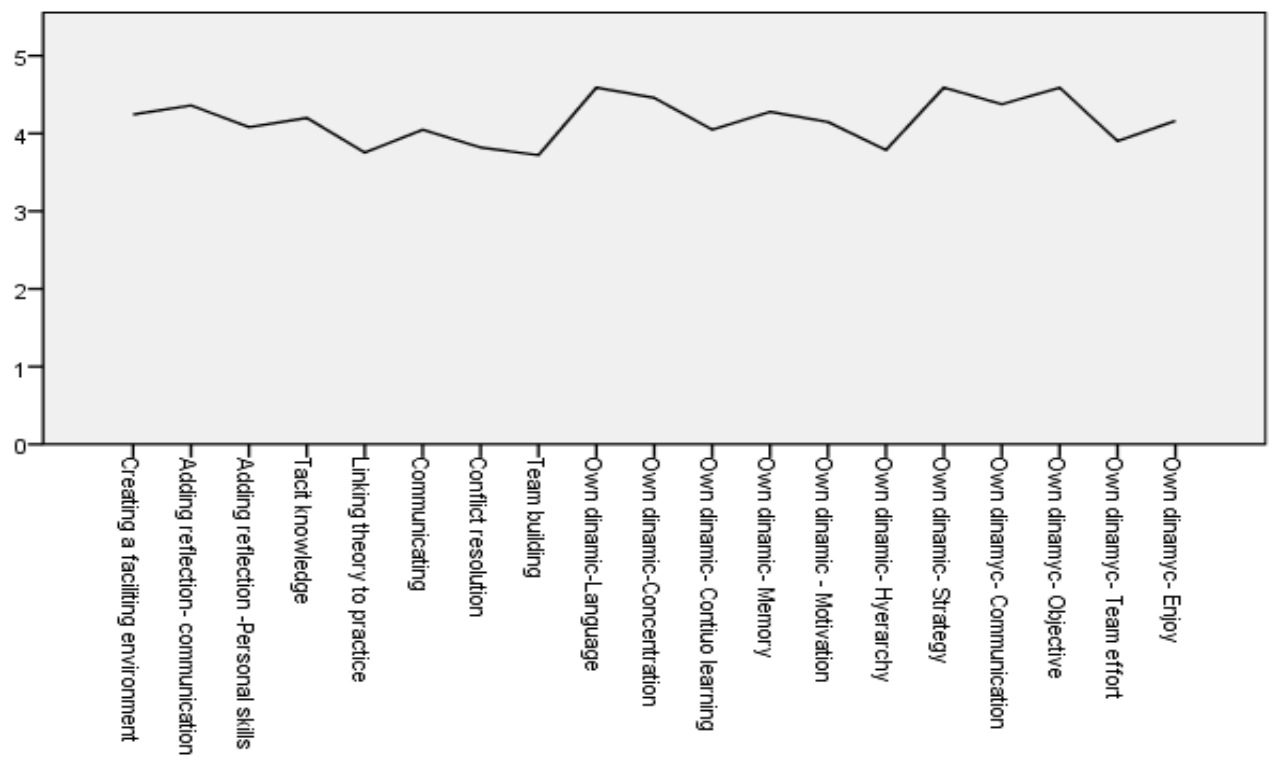

Figure 1. Statistic mean of the variables used.

Subsequently, a cluster analysis was performed to determine whether similar behavior patterns, were present for the variables making up the self-connection as well as for the connection with others. All of them were significant, with the exception of tacit knowledge, which had a value of 0.595 . The following illustration reveals two clear behaviors. Cluster 2, composed of 37 cases, grouped the students who most positively assessed the different variables, with values of 4 and 5, mainly in terms of creating a facilitating environment, and 
adding reflection-communication, which concerns self connection. Cluster 1 consisted in 24 cases with lower values and followed a similar pattern. Yet the view on the assessment of the dynamics was more critical with an average oscillating between 3 and 4. On the other hand, we also analyzed if the degree of study could influence the results, but we found no statistically significant relationships in any of the cases.



Figure 2. Cluster analysis.

\section{Conclusions}

As observed both in the review of other work and through the results obtained in this study, the use of gamification in learning processes is highly valued by students in terms of the development of the own dynamics as well as the implicit learning that it proposes.

LEGO blocks are one of the tools that can be used. They facilitate the assimilation of knowledge when working with tangible elements and they are versatile enough to adapt to different dynamics. The game presented in this research, aimed at improving communication and teamwork, focuses more on the connection with others. Although the results obtained after analyzing the responses to the questionnaires were very positive for all the items analyzed, the items linked to self-connection were the most prominent, fundamentally those linked to communication and development in one's own environment. Valuing teamwork came in second place. The free text answer questions corroborate these 
results. The students emphasize three items, which most like about activity carried out: to experience how the organization works in a teamwork, the different roles that the members acquire and, mainly, the evolution of communication in the group through the design of a common language of all the members that enables the improvement as a team. On the opposite side, they indicate as a negative point having to develop the dynamics under the pressure of time, since this is limited, for this reason, the most number of participants requested to improve this problem by enabling an initial time to design a common team strategy.

For all of the above, we may affirm that the use of these dynamics facilitates the learning process (Buckley, 2015, Erwin, 2000, McNamara et al., 1999) while also motivating students. It would be interesting for future research to look into why teamwork and conflict resolution was not so relevant. The sample under analysis could also be extended to include students from different fields of knowledge and qualification to see whether the patterns outlined in this paper hold.

\section{References}

All, A. \& Havens, R.L. (1997). Cognitive/Conceptual Mapping: A Teaching Strategy for Nursing. Journal of Advanced Nursing 25 (6), 1210-1219

Bethke, K. \& Rogers, C. (2013). Engineering design-based science, science content performance and science attitudes in elementary school. Journal of Engineering Education, 120 (4), 513-540.

Bonwell, C.C. \& Eison, J. A. (1991). Active Learning: Creating Excitement in the Classroom. ASHE-ERIC Higher Education Report, Washington DC: School of Education and Human Development, George Washington University.

Buckley, C. (2015). Conceptualizing plagiarism: Using Lego to construct students' understanding of authorship and citation. Teaching in Higher Education, 20 (3).

Connolly, T.M., Boyle, E.A., MacArthur, E., Hainey, T., \& Boyle, J. M. (2012). A Systematic literature review of empirical evidence on computer games and serious games. Computers \& Education, 59, 661-686.

Daines, J., Daines, C. \& Graham, B. (1998). Adult Learning Adult Teaching. England: Lavenham Press.

Erwin, B. (2000). Creative projects with LEGO mindstrorms. Addison-Wesley.

Gadomska, A. (2015). Using LEGO blocks for technology-mediated task-based English language learning. Teaching English with Technology, 15 (2), 120-132.

Gauntlett, D. (2007). Creative Explorations: New Approaches to Identities and Audiences. U.K.: Routledge

Hamari, J., \& Koivisto, J. (2013). Social motivations to use gamification: An empirical study of gamifying exercise. In Proceedings of the 21st European Conference on Information Systems, Utrecht, The Netherlands, June 5-8, 2013. 
Horwarth, J. \& Morrison, T. (1999). Effective Staff Training in Social Care: From Theory to Practice. London: Routledge.

Hunt, C. (2006). Travels with a Turtle: Metaphors and the Making of a Professional Identity. Reflective Practice 7 (3), 15-332

Lawlor, M., \& Handley, P. (1996). The Creative Trainer: Holistic Facilitation Skills for Accelerated Learning. London: McGraw Hill

Li, Y., Huang, Z., Jiang, M., \& Chang, T. W. (2016). The Effect on Pupils' Science Performance and Problem-Solving Ability through Lego: An Engineering Design-based Modeling Approach. Educational Technology \& Society, 19 (3), 143-156.

McNamara, S., Cyr, M., Rogers, C., \& Bratzel, B. (1999). LEGO brick sculptures and robotics in education. Paper presented at the American Society for Engineering Education Annual Conference \& Exposition, Charlotte, NC.

Osmond, J. \& Darlington, Y. (2005). Reflective Analysis: Techniques for Facilitating Reflection. Australian Social Work, 58 (1), 3-14.

Papert, S. (1980). Mindstorms: Children, computers, and powerful ideas. New York, NY: Basic Books.

Papert, S., \& Harel, I. (1991). Situating Constructionism. In Constructionism, edited by S. Papert and I.Harel. Norwood: Ablex Publishing.http://www.papert.org/articles/SituatingConstructionism.html.

Race, P. (2001). The Lecturer's Toolkit: A Practical Guide to Learning, Teaching and Assessment. 2nd ed. London: Kogan Page, Ltd.

Ruch, G. (2002). From Triangle to Spiral: Reflective Practice in Social Work Education, Practice and Research. Social Work Education 21 (2), 2002

Scannapieco, F.A.(1997). Formaldebate:Anactivelearningstrategy. Journal of Dental Education, 61, 955-961.

Switon, L. (2016). Building communication skills. Management for the Rest of Us. Available in: http://mftrou.com/communication-skills-game/

Werbach, K., \& Hunter, D. (2012). For the Win: How Game Thinking Can Revolutionize Your Business. London: Wharton Digital Press.

Zichermann, G., \& Cunningham, C. (2011). Gamification by Design: Implementing Game Mechanics in Web and Mobile Apps. O'Reilly Media. 